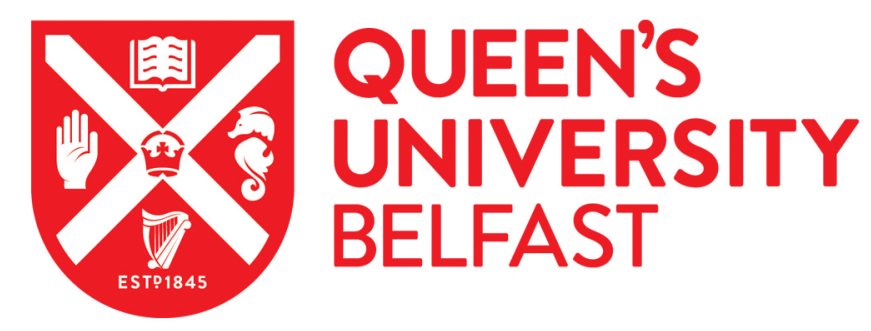

\title{
The Role of Arg228 in the phosphorylation of galactokinase: The mechanism of GHMP kinases by QM/MM studies
}

Huang, M., Li, X., Zou, J-W., \& Timson, D. J. (2013). The Role of Arg228 in the phosphorylation of galactokinase: The mechanism of GHMP kinases by QM/MM studies. Biochemistry, 52(28), 4858. https://doi.org/10.1021/bi400228e

Published in:

Biochemistry

Document Version:

Early version, also known as pre-print

Queen's University Belfast - Research Portal:

Link to publication record in Queen's University Belfast Research Portal

\section{General rights}

Copyright for the publications made accessible via the Queen's University Belfast Research Portal is retained by the author(s) and / or other copyright owners and it is a condition of accessing these publications that users recognise and abide by the legal requirements associated with these rights.

Take down policy

The Research Portal is Queen's institutional repository that provides access to Queen's research output. Every effort has been made to ensure that content in the Research Portal does not infringe any person's rights, or applicable UK laws. If you discover content in the Research Portal that you believe breaches copyright or violates any law, please contact openaccess@qub.ac.uk. 


\title{
Role of Arg228 in the Phosphorylation of Galactokinase: The Mechanism of GHMP Kinases by Quantum Mechanics/Molecular Mechanics Studies
}

\author{
Meilan Huang, ${ }^{* \dagger}{ }^{\dagger}$ Xiaozhou Li, ${ }^{\dagger}$ Jian-Wei Zou, $^{\ddagger}$ and David J. Timson ${ }^{\S}$ \\ †School of Chemistry and Chemical Engineering, Queen’s University Belfast, David Keir Building, Stranmillis Road, Belfast BT9 5AG, \\ U.K. \\ ${ }^{\ddagger}$ School of Chemical and Biological Engineering, Ningbo Institute of Technology, Zhejiang University, Ningbo 315100, China \\ ${ }^{\S}$ School of Biological Sciences, Queen's University Belfast, 97 Lisburn Road, Belfast BT9 7BL, U.K.
}

Supporting Information

\begin{abstract}
GHMP kinases are a group of structurally related small molecule kinases. They have been found in all kingdoms of life and are mostly responsible for catalyzing the ATP-dependent phosphorylation of intermediary metabolites. Although the GHMP kinases are of clinical, pharmaceutical, and biotechnological importance, the mechanism of GHMP kinases is controversial. A catalytic base mechanism was suggested for mevalonate kinase that has a structural feature of the $\gamma$-phosphate of ATP close to an aspartate residue; however, for one GHMP family member, homoserine kinase, where the residue acting as general base is absent, a direct phosphorylation mechanism was suggested. Furthermore, it was

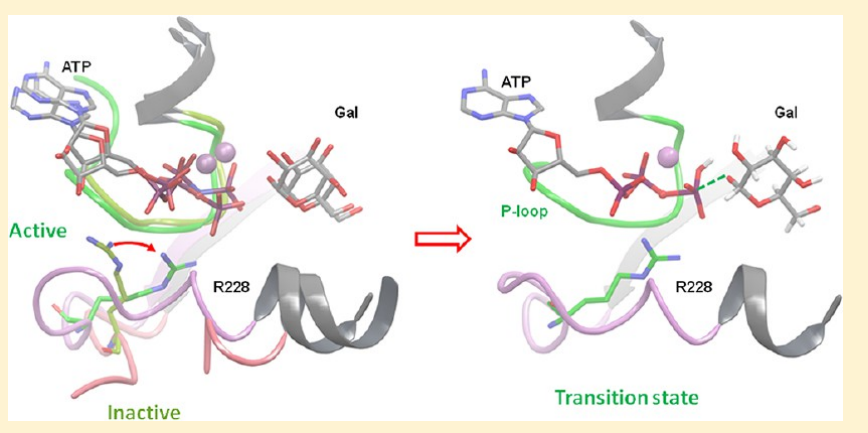
proposed by some authors that all the GHMP kinases function by a similar mechanism. This controversy in mechanism has limited our ability to exploit these enzymes as drug targets and in biotechnology. Here the phosphorylation reaction mechanism of the human galactokinase, a member of the GHMP kinase family, was investigated using molecular dynamics simulations and density functional theory-based quantum mechanics/molecular mechanics calculations (B3LYP-D/AMBER99). The reaction coordinates were localized by potential energy scan using an adiabatic mapping method. Our results indicate that a highly conserved Glu174 captures Arg105 in the proximity of the $\alpha$-phosphate of ATP, forming a H-bond network; therefore, the mobility of ATP in the large oxyanion hole is restricted. Arg228 functions to stabilize the negative charge developed at the $\beta, \gamma$ bridging oxygen of the ATP during bond cleavage. The reaction occurs via a direct phosphorylation mechanism, and the Asp 186 in the proximity of ATP does not directly participate in the reaction pathway. Because Arg228 is not conserved among GHMP kinases, reagents which form interactions with Arg228, and therefore can interrupt its function in phosphorylation, may be developed into potential selective inhibitors for galactokinase.
\end{abstract}

GHMP kinases are a group of structurally related small molecule kinases. ${ }^{1}$ They have been found in all kingdoms of life and are mostly responsible for catalyzing the ATP-dependent phosphorylation of intermediary metabolites. The family is named after four members (galactokinase (GALK), homoserine kinase (HSK), mevalonate kinase (MK), and (prokaryotic) phosphomevalonate kinase (PMK)) and has been expanded to include archaeal shikimate kinase, L-threonine kinase, $\mathrm{N}$ acetylgalactosamine kinase (GALK2), glucuronokinase, arabinose kinase, galacturonic acid kinase, mevalonate diphosphate decarboxylase (MDD), and 4-(cytidine 5'-diphospho)-2-Cmethyl-D-erythritol kinase (CDP-Me kinase).

All of these proteins share a common fold consisting of a mixture of $\alpha$-helices and $\beta$-sheets, organized into $\mathrm{N}$ - and $\mathrm{C}$ terminal domains which are arranged in a $\mathrm{V}$-shape. This creates a central cleft, and the active site is located at the base of this cleft (Figure 1). A number of conserved motifs are distinguished, ${ }^{2}$ among which the MgATP binding motifs (usually denoted II and III) are highly conserved and motif I, which is involved in recognition of the other substrate, shows greater variation (Figure 2). Of all the GHMP kinases, GALK is the best characterized at the structural level, with highresolution crystal structures available for a number of species. $^{3-5}$

The GHMP kinases are of clinical, pharmaceutical, and biotechnological importance. Mutations in the gene encoding MK are associated with hyperimmunoglobulinemia D syndrome (HIDS) and mevalonic aciduria (MVA). ${ }^{6-8}$ Mutations in the gene encoding human GALK cause the hereditary disease type II galactosemia. $^{9-12}$ This enzyme is also an

Received: February 22, 2013

Revised: June 18, 2013

Published: June 20, 2013 


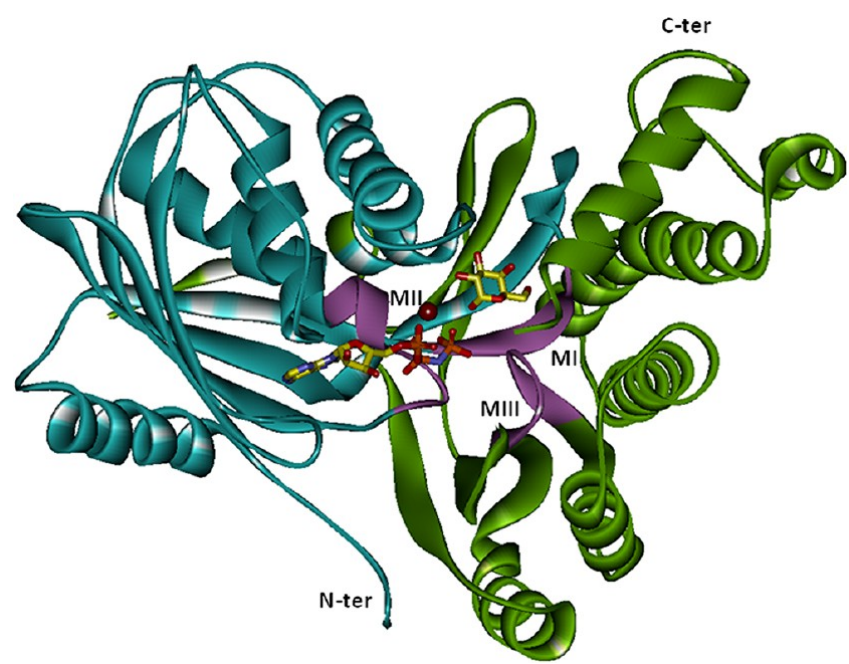

Figure 1. Crystal structure of human GALK. The N-terminal domain is cyan, and the C-terminal domain is green. Motifs I-III are purple. The galactose and ATP in the active siet are shown by a stick model, and the $\mathrm{Mg}^{2+}$ ion is shown as a purple ball.

important drug target. Although type II galactosemia is a relatively mild disease (the main symptom is cataracts, which can be permanently resolved by surgery), types I and III galactosemia (caused by mutations in the genes encoding other galactose-metabolizing enzymes) can lead to severe and irreversible damage to the liver and brain. The symptoms are suggested to be caused by accumulation of galactose 1phosphate, the product of the phosphorylation catalyzed by GALK. Therefore, inhibition of the upstream enzyme GALK would prevent the buildup of toxic galactose 1-phosphate in types I and III and, in effect, convert them into the far milder type II. Recently, a number of novel inhibitors of human GALK have been identified. ${ }^{13-15}$ Some other GHMP kinases are also important drug targets; for example, PMK and CDP-Me kinase are unique to bacteria and exhibit essential functions in these organisms and, therefore, are potential targets for novel antibiotics. ${ }^{16}$ There has been also increasing interest in the biotechnological exploitation of some GHMP kinases. GALKs from several species are being used as biocatalysts, and some have been engineered to expand their substrate specificity with the aim of using the enzyme in the "green chemistry" synthesis of sugar 1-phosphates, the precursors of carbohydratecontaining antibiotics. ${ }^{17-19}$

The mechanism of GHMP kinases is controversial. The structure of MK shows that mevalonate and the $\gamma$-phosphate of ATP are close to an aspartate residue, which is largely conserved among GHMP kinases. ${ }^{20}$ It was postulated that this residue acts as a general base, abstracting a proton from the hydroxyl group in mevalonate. This converts mevalonate into an excellent nucleophile, which then attacks the $\gamma$-phosphorus of ATP. A nearby lysine residue was believed to maintain the aspartate residue in the deprotonated state and lower the $\mathrm{p} K_{\mathrm{a}}$ of the sugar to facilitate the proton transfer. This catalytic base mechanism was supported by site-directed mutagenesis studies. ${ }^{20}$ Removal of the putative active site base reduces the rate substantially. Similarly, the rate is reduced by alteration of the lysine residue. ${ }^{21,22}$ Similar arrangements of the active site residues are observed in most of the other GHMP kinases, such as GALK, where arginine (Arg37) replaces lysine. Recently a combined molecular modeling and mutagenesis study revealed that removal of the putative active site base (Asp186) in human GALK results in destabilization of the protein and loss of detectable activity, as does removal of the adjacent cationic residue Arg37. ${ }^{23}$ Preliminary quantum mechanics/molecular mechanics (QM/MM) calculations suggested that Asp186 appeared to polarize the hydroxyl group in the sugar. However, whether this results in bond breakage or weakening is unclear, and the role of the surrounding residues in the active site is not understood. ${ }^{23}$

In HSK, another member of the GHMP family, the aspartate and lysine in the proximity of ATP are replaced with asparagine and threonine, respectively; therefore, HSK does not have a corresponding base to activate the hydroxyl group in the substrate. Instead, the $\gamma$-phosphoryl group directly grabs a proton from the hydroxyl group of homoserine (Hse). This direct phosphorylation mechanism represents another possible mechanism for GHMP kinases. ${ }^{24}$ Structural studies on $\mathrm{N}$ acetylgalactosamine kinase (GALK2) suggested that this mechanism may occur even in those enzymes which have a basic residue in the active site. The authors of this study considered that the relevant aspartate (Asp190) was too far from the sugar to abstract a proton. ${ }^{25}$ This was supported by the lack of a $\mathrm{pH}$ effect on the steady-state kinetic parameters of some of the enzymes, e.g., S. cerevisiae GALK (Gallp), ${ }^{26 a}$ and the lack of a deuterium kinetic isotope effect in the human enzyme. ${ }^{26 \mathrm{~b}}$ However, either of the two proposed mechanisms for GHMP kinases might work for human GALK1. ${ }^{2,25}$

Previous studies of GALK inhibitor discovery have been focused on high-throughput screening. ${ }^{13-15}$ Development of "suicide" inhibitors has become an interesting area because this represents a potentially effective strategy for selective inhibition of the kinase. Recently, mechanism-based inhibitors were designed to inactivate mevalonate pathway GHMP kinases. ${ }^{27}$ However, the controversy about the mechanism in GHMP kinases has limited our ability to exploit these enzymes as drug targets and in biotechnology.

The mechanism of GHMP kinases can be elucidated by investigation of the reaction pathway by theoretical calculation, which is not approachable by experiments. In the present work, the phosphorylation reaction mechanism of GALK was studied by molecular dynamics simulation and hybrid QM/MM calculations. It was demonstrated that the reaction's phosphorylation mechanism occurs via direct phosphorylation, instead of the previously hypothesized catalytic base mechanism. The dynamic aspect of the GALK structure, in particular the structure in complex with the transition state, would provide a starting point for rational design of mechanism-based GALK inhibitors and provide guidance for biotechnology research into broadening the specificity of the enzyme.

\section{MATERIALS AND METHODS}

Protein Preparation. Chain A of the crystal structure of human GALK (PDB code 1WUU) was used. ${ }^{3}$ Ser230 and Leu231, which are missing in the experimentally resolved structure, were built using the loop refinement tools in Discovery Studio 2.5 (Accelrys, Inc.). The selenomethionine residues were mutated back to standard methionine, and the nitrogen atom bridging the $\beta$ - and $\gamma$-phosphates in the bound AMP.PNP was altered to an oxygen atom yielding an ATP molecule. Two water molecules were added to saturate the coordination of $\mathrm{Mg}^{2+}$ based on the positions of the two coordinated waters in the crystal structure of GALK2. ${ }^{25}$ The 
R37

Hsa-GALK1

Hsa-GALK2

Sco-Gallp

Sco-Gal3p

Pfu-GAL

MJa-MK

Hsa-MK

Spn-PMK

Mja-HSK

Sce-HSK

TKO-POK

Tba-PoK

Hwa-PoK

Hsa-GALK1

Hsa-GALK2

Sce-Gallp

Sce-Gal3p

Pfu-GALK

Mja-MK

Spn-PMK

Sce-PMK

Mja-HSK

Sce-HSK

TkO-POK

Tba-PoK

Hwa-PoK

Hsa-GALK1

Hsa-GALK2

Sco-Gallp

Pfu-GAIK

Pfu-GA
Mja-MR

Mja-Mk
Hsa-MK

Hsa-MK

Spn-PMK
Sce-PMK

Mja-HSK

Sco-HSK

TKO-POK

Tba-PoK

Hwa-PoK

Hsa-GALK1

Hsa-GALK2

Sce-Gallp

Sce-Gal3p

Pfu-GALK

Mja-MK

Hsa-MK

Spn-PMK

SCo-PMK

Mja-HSK

Sce-HSK

TKO-POK

Tba-PoK

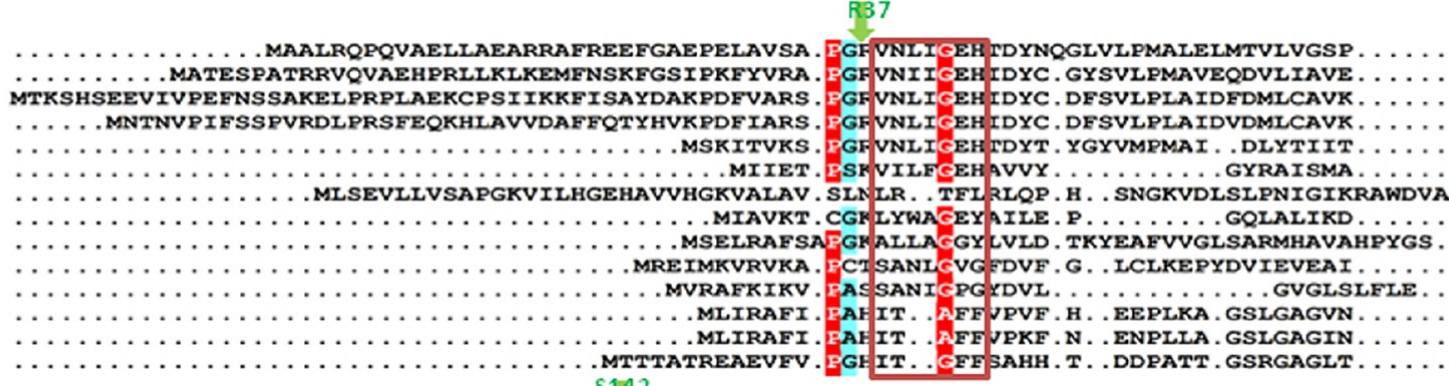
MATESPATRRVQVAEHPRILKLKEMFNSKFGSIPKFYVRA

GF VNII

MDYNQGLVLPMALELMTVLVGSP $\ldots \ldots$ ICEH IDYC. GYSVLPMAVEQDVIIAVE. . . . . MNTNVPIFSSPVRDLPRSFEOKHLAVVDAFFOTYHVKPDFIARS

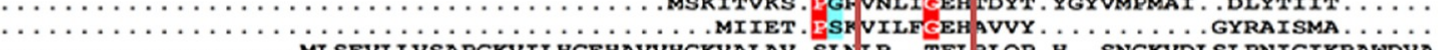
HGKVALAV. SLNLR. TFIRLQP. H. . SNGKVDLSLPNIGIKRAWDVA MSELPAESAPGH ALIACGYLVID TKYEAFVVGLSARMHAVAHPYGS $\$ 142$

PA. APLPG . . . . . . FSAVVVSSVELC G. . GLSSSASL . EVATYTFLQQL. CPDSG. . . . . . . . . T. . IAARAQVCQQA

GL. SNLTG. . . . . . . MNCLVDGNIEPSS . . GLSSSSF L . VCCAGLVTLTV. LGRNL . . . . . . . . . . . KVELAEICAKS

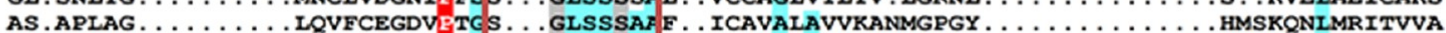

NN. TPLVG. . . . . . A AQIFCQSDIPTCG. . GL . SSF F. TCAAALATIRANMGKNF. . . . . . . . . DISKKDLTRITAVA

GYKIGG. . . . . . . LKGKITGDLELGA . . GLSSSASE. EVGILEVLNQL . YNLNI . . . . . . . . . . . PLKKALLAKKA

NI.EPKTG . . . . . . FKINISSKIEIS C . . GLGSSAS I. .TIGTIKAVSGF. YNKEL . . . . . . . . . . . . DDEIAKLGYMV

CR. KQRALPS . . . . . . LDIVVWSELFPCA . . GLGSSA Y . SVCLAAALITV. CEEI PNPLKDGDCVNRWTKED . . LELINKWAFQG

AVRGQNLRP . . . . . . FSLAIYGKMERE GKKFGLGSSGSV. .VVLVVKALIAL . YNLSV . . . . . . . . . . . D . QNLLFKLTSAV

SQ.EDSVTEHRGNRRLS. FHSHRIEEVE. . KT . . GLGSSACLVTVLTTALASFFV. SDLEN . . . . . . NVDKYREV . IHNLAQVAHCQ

NIGKG . . . . . . . . VKITIKKGVKACS . . GLGSSAF S . SAGTAYAINEL . FKLNL . . . . . . . . . . KLKLVDYASYG

NI.RNFPSG . . . . . . TKVHVSNPIFLGR . . GLGSSGF A. VVAGVILGNEV. AQLGF. . . . . . . . . . . . KQRMLDYCLMI

VP. KDFLGE $\ldots \ldots \ldots$ VEVWQYFDFPNG Y . . GFGNSACG. ALGTALALSYA . FGGTW . . . . . . . . . . . . . LRAAQLAHEA

TP. QEFKGE. . . . . VEIWQYFDFENCY . . GFGNSAC E19T.DD..... D186 . . INVNAQTALELCA

GFGVSGF M. . TLGVAFGSNAV ADKTN.

RZZ2 - . T TRAESALITAAHCA

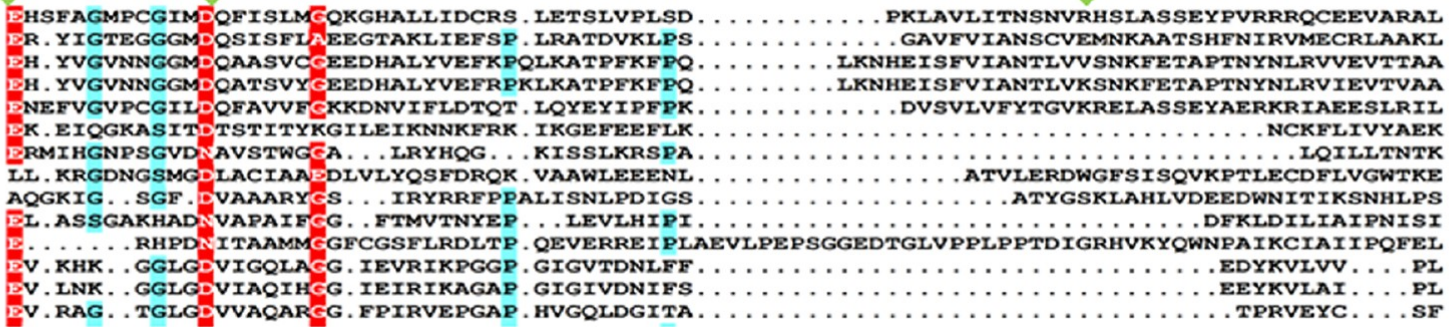
GAVEVIANSCYEMNKAATSHFNIRUMECRLAAKI

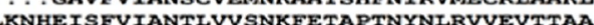

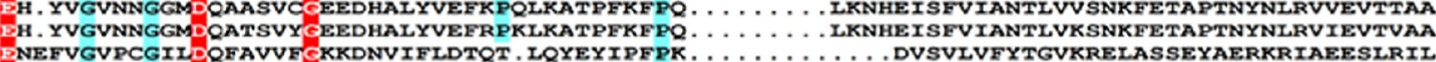
DNEFVGVPCGIIDQEAVVFGKKDNVIFLDTQT. LQYEYIPFPK. $\cdots \cdots \cdots \cdots \ldots \ldots$ DVSVLVFYTGVKRELASSEYAERKRIAEESLRII IKGETERT. AQGKIG. . SGF. DVAAARYGS... TRYRRFPPALISNLPDIGS . ATVIERDWGESISOVKRTIE. LQILLTNTK ATYGSKLAHLVDEEDWNITIKSNHLPS

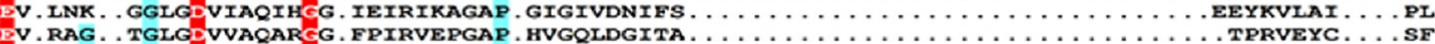

Hwa-PoK

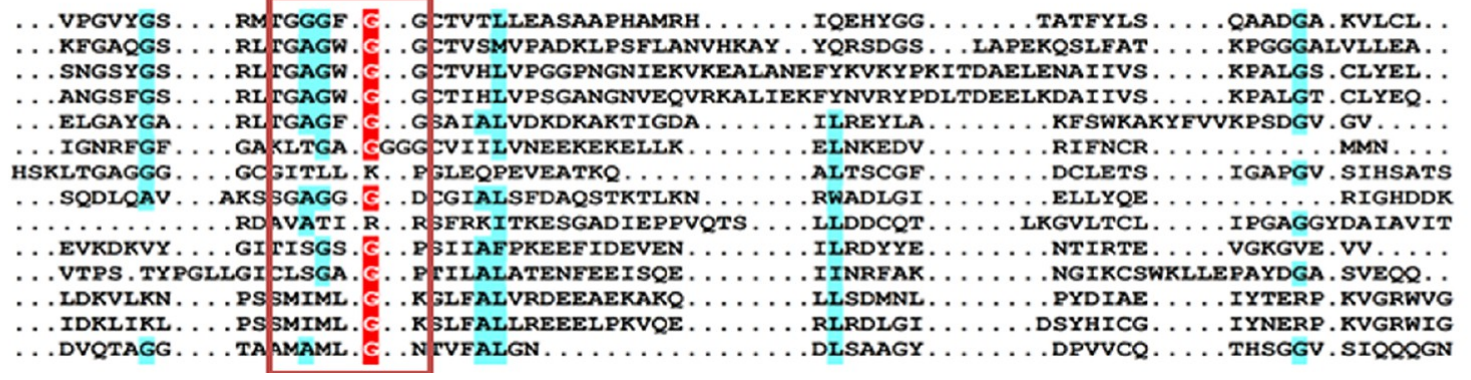

Figure 2. Sequence alignments of the GHMP kinases with their homologue kinase PoKs using the MUSCLE multiple-sequence alignment server from the European Bioinformatics Institute. Sequence alignments of 11 representative GHMP and 3 PoK kinases are shown. The three ATP binding motifs I-III are labeled with red boxes. The positions of residues Arg37, Arg105, Glu174, Asp186, and Arg228 are highlighted by green arrows. Protein name abbreviations are as follows: GALK, galactokinase; MK, mevalonate kinase; PMK, phosphomevalonate kinase; HSK, homoserine kinase; MDD, mevalonate diphosphate decarboxylase; PoK, pantoate kinase; PanK, pantothenate kinase; AK, archaeal kinase; HP, hypothetical protein; UNK, unknown. Species name abbreviations are as follows: Hsa, Homo sapiens; Sce, Saccharomyces cerevisiae; Pfu, Pyrococcus furiosus; Spn, Streptococcus pneumoniae; Mja, Methanococcus jannaschii; Tko, Thermococcus kodakarensis; Tba, Thermococcus barophilus; Hwa, Haloquadratum walsbyi; Hba, Halobacterium sp. NRC-1. Accession numbers: Hsa-GALK1 (P51570.1), Hsa-GALK2 (Q01415.1), Sce-Gal1p (NP 009576.1), SceGal3p (NP_010292.1), Pfu-GALK (AAL80569.1), Mja-MK (AAB99088.1), Hsa-MK (NP_000422.1), Spn-PMK (NP_357934.1), Sce-PMK (AAA34596.1), Mja-HSK (AAB99107.1), Hce-HSK (P17423.4), Tko-PoK (Q5JHF1.1), Tba-PoK (YP 004072154.1), Hwa-PoK (CAJ51400.1). Other GHMP kinase or PoK homologous sequences used for the alignment but not shown are Has-MDD (NP_002452.1), Hba-HP (AAG18848.1), Archaeoglobus fulgidus HP (AAB89596.1), Mja-HP (AAB98974.1), Methanopyrus kandleri AK (AAM01947.1), Pyrobaculum aerophilum HP (AAL64892.1), Aeropyrum pernix HP (BAA80948.2), Sulfolobus solfataricus HP (AAK42544.1), Cenarchaeum symbiosum AK (ABK78124.1), Haloarcula marismortui UNK (AAV46584.1), Methanococcoides burtonii MDD (ABE52109.1), Methanococcus maripaludis HP (CAF29954.1), Methanosaeta thermophila PanK (ABK15208.1), Methanosarcina acetivorans HP (AAM04698.1), Methanosarcina barkeri PanK (AAZ72136.1), Methanosarcina mazei (AAM31978.1), Methanosphaera stadtmanae AK (ABC57568.1), Methanospirillum hungatei PanK (ABD40583.1), Methanothermobacter thermautotrophicus (AAB85083.1) Natronomonas pharaonis PoK (CAI48513.1), Nitrosopumilus maritimus GHMP kinase (ABX13614.1), Pyrococcus abyssi AK (CAB49305.1), P. furiosus HP (AAL81993.1), Pyrococcus horikoshii HP (BAA30946.1), Sulfolobus acidocaldarius AK (AAY80312.1), and Sulfolobus tokodaii HP STK_05300 (BAB65525.1).

protonation states of histidines in GALK were examined using protein preparation in Maestro (Schrödinger, Inc.).

Molecular Dynamics Simulation. Molecular dynamics (MD) simulation was performed using the AMBER 10 package
(University of California). ${ }^{28}$ The Amber Parm 99 force field parameters were used. ${ }^{29}$ The partial charges of galactose, $\mathrm{Mg}^{2+}$, and ATP were obtained by single-point charge calculation at the HF/6-31G(d) level of theory using the Gaussian 09 
package, ${ }^{30}$ and the RESP partial atomic charges were obtained using antechamber encoded in AMBER 10. The protein was soaked with a TIP3P water box with a minimum distance of $8 \AA$ to the boundary of the protein. The size of the box was 70.504 $\times 82.631 \times 87.672 \AA^{3}$. Seven sodium ions were added into the water box to maintain the neutral system.

The protein together with the ligand (ATP) and the substrate (galactose) was subjected to 1250 steps of steepest descent minimization followed by 1250 steps of conjugate gradient minimization with a restrained force constant of 0.5 $\mathrm{kcal} \mathrm{mol}{ }^{-1} \mathrm{~A}^{-2}$. ${ }^{31}$ The system was then heated moderately from 0 to $300 \mathrm{~K}$ for $50 \mathrm{ps}$, using the Langevin dynamics method ${ }^{32}$ with a collision frequency of $5.0 \mathrm{ps}^{-1}$. A periodic boundary condition was applied, and equilibration was carried out with the NVT ensemble at $300 \mathrm{~K}$ for another 50 ps without harmonic constraints. The particle mesh Ewald method ${ }^{33}$ was used to consider the long-range electrostatic interactions. The cutoff distance of nonbonded van der Waals force was $10 \AA$. The SHAKE method ${ }^{34}$ was used to constrain the covalent bonds involving hydrogen atoms. A time step of 1 fs was used, and 5 ns $\mathrm{MD}$ simulation was performed with the NPT ensemble at a reference pressure of $1 \mathrm{~atm}$ at $300 \mathrm{~K}$. Cluster analysis of the MD trajectory was performed by ptraj command encoded in the AMBER 10 package.

QM/MM Simulation. The QM/MM calculations were performed by a two-layer ONIOM method (B3LYP-D, AMBER) $)^{35,36}$ implemented in Gaussian 09 (Gaussian, Inc.). The truncated Asp186, Arg37, Ser142, Glu174, Arg228, and ATP as well as galactose, $\mathrm{Mg}^{2+}$ ion, and two structural waters (49 heavy atoms in total) were treated as a high-level layer by a DFT-QM method, and the rest of the system was treated as a lower-level layer by a MM method (Figure 3).

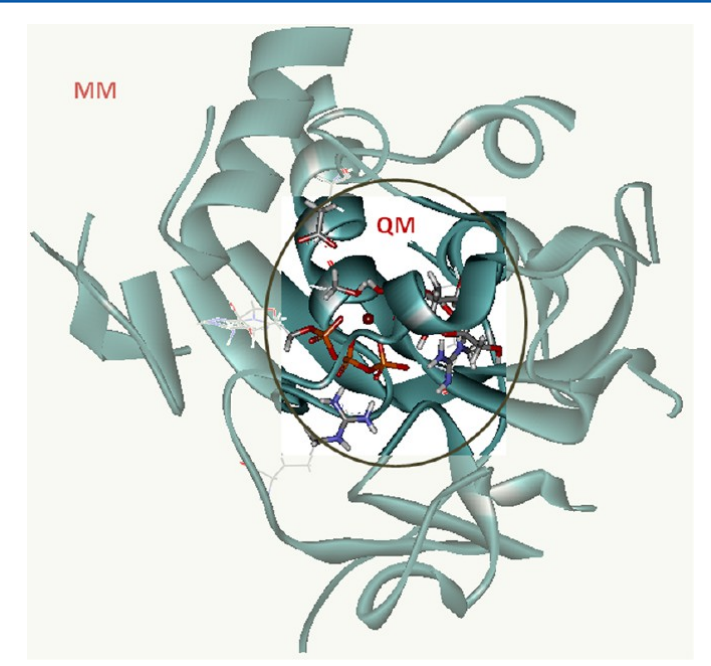

Figure 3. $\mathrm{QM} / \mathrm{MM}$ partition of the protein. The inner $\mathrm{QM}$ core including galactose, ATP, $\mathrm{Mg}^{2+}$, two structural water molecules, Arg37, Asp186, Glu174, and Arg228 is treated by B3LYP-D method, and the outer layer is treated by molecular mechanics using AMBER force field.

The overall charge of the $\mathrm{QM}$ region is -2 . The $\mathrm{QM}$ region was optimized at the B3LYP-D/6-31G(d) level of density functional theory, ${ }^{37}$ and the MM region was optimized by the Amber Parm 99 force field. The electronic embedding scheme was used in the $\mathrm{QM} / \mathrm{MM}$ study. It incorporates the partial charges of the MM region into the quantum mechanical
Hamiltonian and allows the QM wave function to be polarized. To accelerate the calculation, a reduced system including the residues within $12 \AA$ of the active site was used in a potential energy surface scan, using a protocol developed by Tao and coworkers. ${ }^{38,39}$ Residues within $6 \AA$ of the active site (included) were allowed to move while the others were frozen (Supporting Information, Figure S1).

The $\mathrm{p} K_{\mathrm{a}}$ of the protein was calculated based on the QM/ MM-minimized structure using PROPKA 2.0. ${ }^{40,41}$

Simulations of Mutated Human GALK. Five mutated proteins of human GALK were modeled, namely, E174D, E174Q, R105M, R228K, and R228M. The mutated protein structures were subjected to 2500 steps of steepest descent followed by 2500 steps of conjugate gradient minimization; 5 ns $\mathrm{MD}$ simulations were then performed for each minimized mutated proteins, using the same parameters as those used for the wild-type human GALK. The representative conformations for each mutant were retrieved from MD simulations by cluster analysis.

\section{RESULTS AND DISCUSSION}

In the crystal structure of human GALK, the $\mathrm{Mg}^{2+}$ ion is coordinated to Ser142 and to the $\alpha$-, $\beta$-, and $\gamma$-phosphate oxygen atoms. The coordinates of the covalent waters were not resolved. By comparison with the crystal structures of the reactant and product of GALK2, ${ }^{25}$ the positions of two coordinated water molecules in GALK were modeled. This structure was used as the starting structure for investigation of the reaction mechanism of GALK.

The uncertainty in determination of the position of atoms using an X-ray crystallography method can be addressed by MD methods. ${ }^{42} \mathrm{MD}$ simulations were performed to obtain a dynamic structural model of human GALK in aqueous solution. The parameters for ATP, galactose, and magnesium ion obtained by ab initio calculation are shown in the Supporting Information, Table S1.

The conformations obtained from the MD trajectory were clustered into distinct sets on the basis of the RMSD values of the backbone carbon atoms. According to the RMSD values of the backbone carbon atoms, galactose, and ATP (Supporting Information, Figure S2), the last 3.2 ns of the MD simulation was shown to reach equilibrium and was used for cluster analysis. In total, 10 representative conformations were retrieved from the $\mathrm{MD}$ trajectory (Supporting Information, Table S2).

The phosphate binding loop (P-loop) is a motif in proteins which were initially reported by Walker and co-workers in $1983 .^{43}$ It was suggested that the lysine at the end of the P-loop is of great importance for nucleotide binding, stabilizing the negative charge that develops at the $\beta, \gamma$-bridging oxygen of ATP during bond cleavage. ${ }^{44}$ GHMP superfamily members share a consensus sequence (PXXXGLXSSAA) that has been shown to form a unique P-loop structure. ${ }^{45-47}$ The unique loop located on the N-terminus of an $\alpha$-helix near the conserved ATP binding motif II forms a larger than normal oxyanion hole. Among the features that distinguish the nucleotide binding pocket of GHMP kinases from the P-loop of common kinases is the fact that the catalytic lysine residue is "missing" in the GHMP P-loop. The glycine-rich P-loop in human GALK $\left(\mathrm{P}^{134}\right.$ LGGLSSSAS $\left.{ }^{144}\right)$ allows for flexible movement of the loop.

The $\mathrm{Mg}^{2+}$ ion is coordinated to the $\alpha$-, $\beta$-, and $\gamma$-phosphate oxygen atoms of the ATP in GALK. Similar $\mathrm{Mg}^{2+}$ coordination environments are observed in other ATP-binding kinases such 


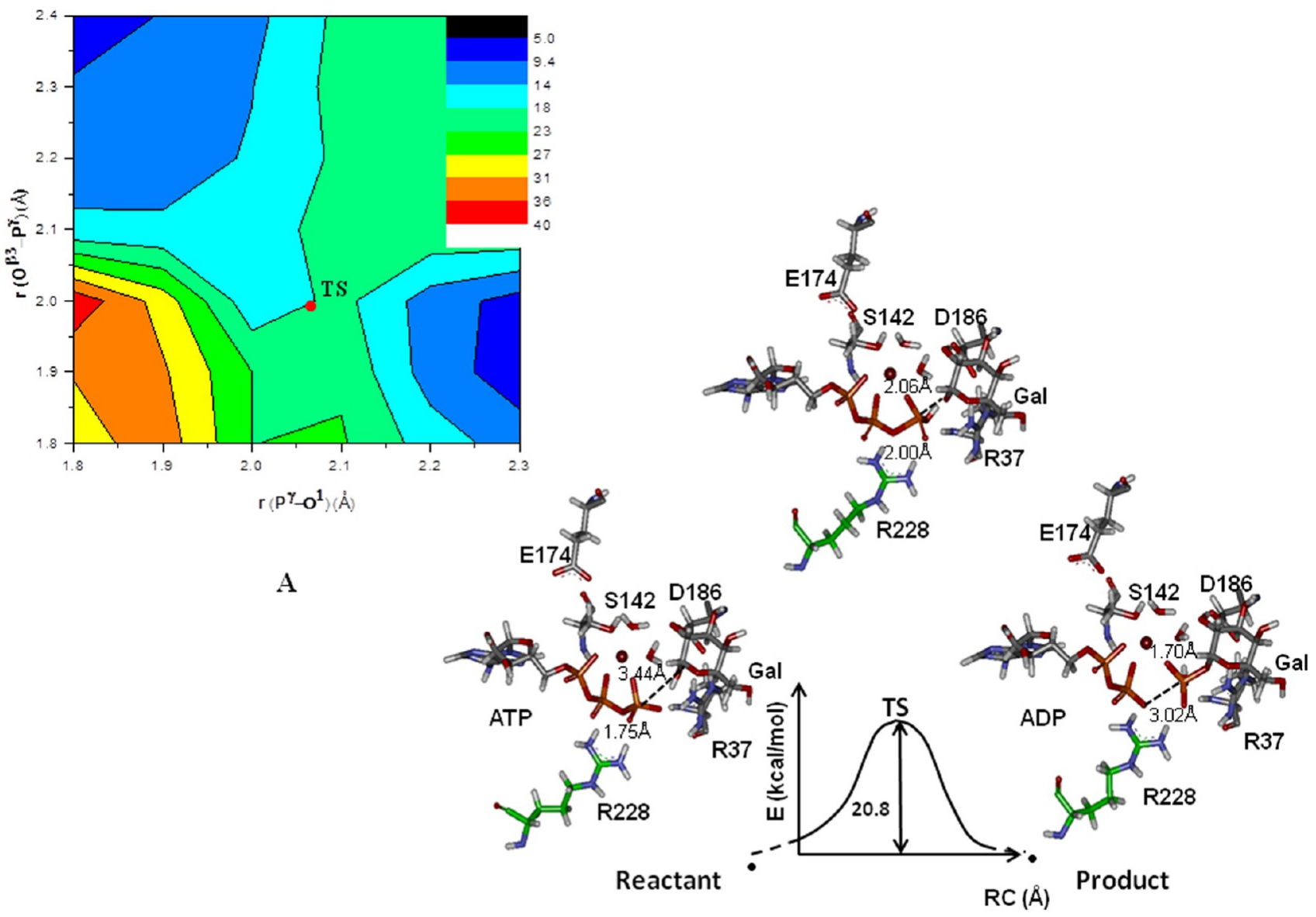

B

Figure 4. (A) Reaction path of human GALK determined by adiabatic mapping. The $x$ and $y$ axes are the distance between the $\gamma$-phosphate $\mathrm{P}$ atom and the $\mathrm{C} 1$ hydroxyl oxygen atom of galactose, $r_{\mathrm{P}^{\gamma}-\mathrm{O}^{1}}$, and that between the $\gamma$-phosphate $\mathrm{P}$ atom and the $\beta, \gamma$-bridging oxygen of the ATP, $r_{\mathrm{O}}{ }^{\beta 3}-\mathrm{P}^{\gamma}$, respcetively. The $z$ axis is the energy with units of kilocalories per mole. (B) Structures of the reactant, TS, and the product obtained by QM/MM calculations with B3LYP-D/6-31G(d) level of theory for the QM part and the AMBER force field for the MM part. The distance between the nitrogen atom of Arg228 and the $\beta, \gamma$-bridging oxygen is labeled by dotted green lines, and $r_{\mathrm{O}^{\beta 3}}-\mathrm{P}^{\gamma}$ and $r_{\mathrm{P}^{\gamma}-\mathrm{O}^{1}}$ are labeled by black dotted lines.

as CheA histidine kinase, epidermal growth factor receptor (EGFR) ErbB3 kinase, and cyclin-dependent protein kinase (CDK2). The reaction mechanism of ErbB3 kinase is direct phosphorylation via a transition state in which the proton on the substrate hydroxyl group is transferred to the $\gamma$-phosphate of ATP, whereas reaction in CDK2 occurs through a catalytic base mechanism where the phosphate transfer is preceded by proton transfer from the hydroxyl group of the substrate to a surrounding aspartic acid. ${ }^{4-50}$ A lysine residue in the active sites of these kinases was shown to stabilize the nucleophilic $\beta, \gamma$-bridging oxygen atom of the ATP during bond cleavage, either directly or via a $\mathrm{H}$-bond network with water molecules. However, no cationic residue is observed at the active site in the crystal structure of human GALK. The closest cationic residue, $\operatorname{Arg} 228$, which is located on a surface loop adjacent to the P-loop, is $7.29 \AA$ from the $\beta, \gamma$-bridging oxygen. We postulated that $\operatorname{Arg} 228$ in the inactive configuration may play a role in the enzymatic reaction. The MD simulation trajectory was inspected, and the distance between the distal guanidinium nitrogen atom of Arg228 and the $\beta, \gamma$-bridging oxygen atom of the ATP was plotted (Supporting Information, Figure S3). Interestingly, it was found that with time evolution Arg228 approaches the $\beta, \gamma$-bridging oxygen, with the distance $r_{\mathrm{N}^{n}-\mathrm{O}^{\beta 3}}$ decreasing from 7.3 to $3.6 \AA$ (Supporting Information, supplementary movie). Thus, the structure has turned into an active configuration in which $\operatorname{Arg} 228$ is prone to stabilizing the negative charge developed at the $\beta, \gamma$-bridging oxygen during bond cleavage.

The representative conformations retrieved from cluster analysis of the MD simulation trajectory were carefully inspected to compare the conformational difference around the ATP binding site, in particular the distance between the $\mathrm{C} 1$ hydroxyl oxygen atom of galactose and the $\mathrm{P}^{\gamma}$ atom of ATP $\left(r_{\mathrm{O}^{1}}-\mathrm{P}^{\gamma}\right)$ and the distance between the $\mathrm{C} 1$ hydroxyl hydrogen atom of the sugar and the carboxylate $\mathrm{O}^{\mathrm{D} 2}$ atom of Asp186 $\left(r_{\mathrm{H}^{1}}-\mathrm{O}^{\mathrm{D} 2}\right)$ because these distances indicate preference of either catalytic base or direct phosphorylation reaction mechanisms. The conformation where Arg228 was closest to ATP (Supporting Information, Figure S3 and Table S2) was selected from the 10 representative structures for the subsequent QM/ MM mechanistic study, as Arg228 in this conformation has the potential to stabilize the $\beta, \gamma$-bridging oxygen of ATP during phosphorylation. The $\mathrm{p} K_{\mathrm{a}}$ of $\operatorname{Arg} 228$ in the QM/MMoptimized reactant of human GALK was calculated, and it was found that the value (9.47) is much lower than the "free solution" value of arginine (12.50). This indicates that Arg228 may act as a potential electrophile to stabilize the negative 
Scheme 1. Two-Dimensional Representation of the Phosphorylation Mechanism of Human GALK

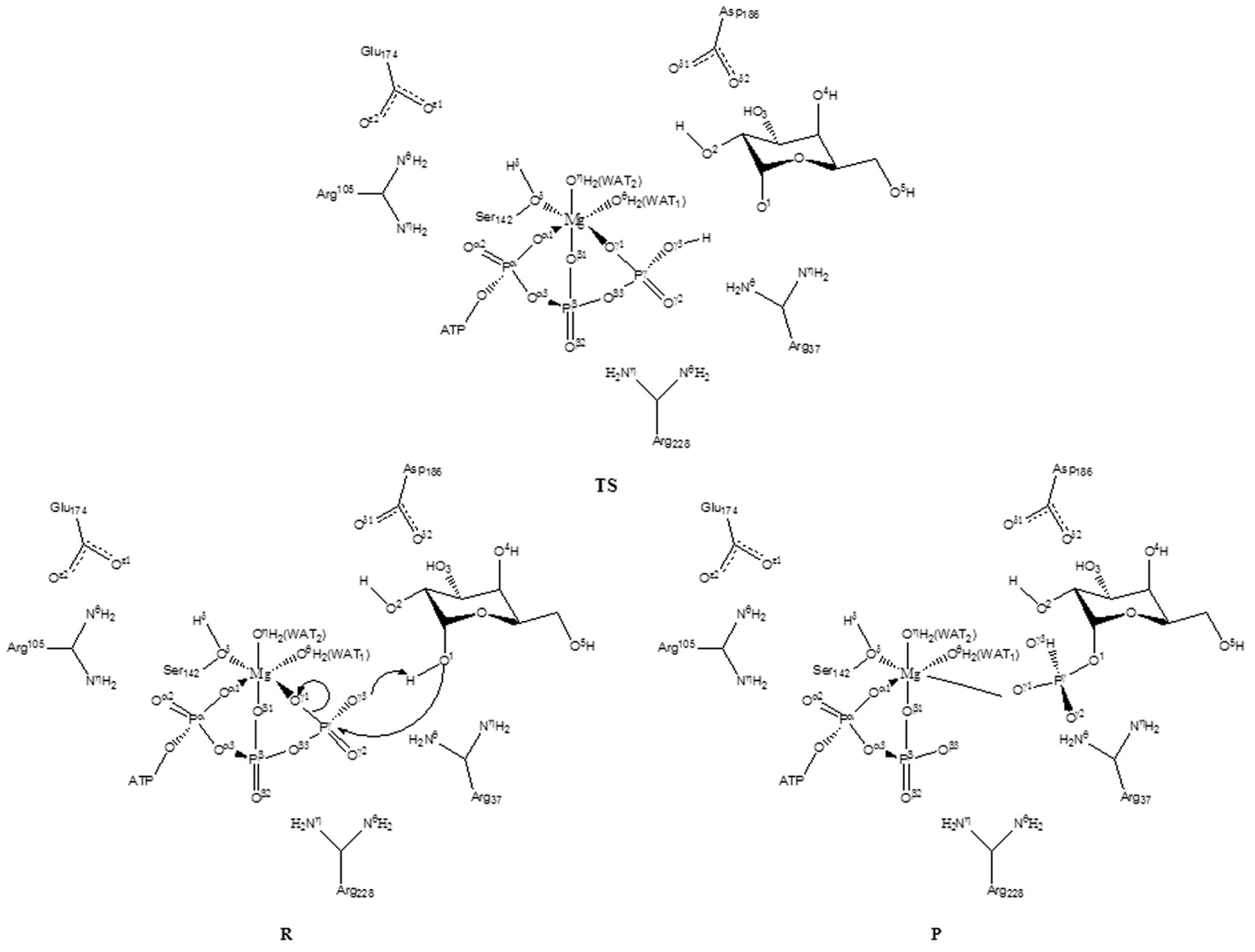

charge developed at the $\beta, \gamma$-bridging oxygen of ATP during bond cleavage.

Recently, a glutamate residue (Glu134) was suggested to be involved in the catalytic reaction of pantoate kinase (PoK), a GHMP kinase necessary for coenzyme A biosynthesis in the Archaea. ${ }^{51}$ The glutamate is largely conserved among GHMP kinases, and the corresponding residue in human GALK (Glu174) is located on an $\alpha$-helix (Figure 2). From the molecular dynamics simulation, it was observed that Arg105 flipped toward Glu174 and ATP and ultimately formed a strong electrostatic interaction with Glu174 (Figure S4).

Combined QM/MM methods are important in the understanding of the mechanism of enzyme-catalyzed reactions. ${ }^{52}$ The conformation selected from the cluster analysis was optimized using QM/MM methods. It was found that in the optimized geometry, Arg105 becomes closer to ATP because of a favorable ionic interaction with Glu174; in the meantime, it forms an $\mathrm{H}$-bond with the $\alpha$-phosphate atom of ATP, thus restricting the movement of ATP in the large oxyanion hole (Figure 4). The potential energy surface (PES) of the human GALK reaction pathway was investigated by the adiabatic mapping method. On the basis of the optimized reactant, the distances of $r_{\mathrm{O}^{1}-\mathrm{P}^{\gamma}}$ and $r_{\mathrm{P}^{\gamma}-\mathrm{O}^{\beta 3}}$ that are directly involved in $\gamma$ phosphate transfer were scanned with an increment of $0.1 \AA$.
A trigonal-bipyramidal transition state that connects the reactant and the product was identified from the PES (Figure 4). It was validated by a unique imaginary frequency of -167.59 $\mathrm{cm}^{-1}$ that corresponds to the $\gamma$-phosphate transfer to the substrate galactose. The reaction coordinates exhibited proton migration from the $\mathrm{C} 1$ hydroxyl group of galactose to the $\gamma$ phosphate oxygen atom of ATP, and the phosphoryl transfer coincides with the proton migration from galactose (Scheme 1). Compared with that of the reactant, the distance between the $\mathrm{C} 1$ hydroxyl oxygen and the $\mathrm{P}^{\gamma}$ atom in the transition state is shortened from 3.44 to $2.06 \AA$ and the distance between $\mathrm{P}^{\gamma}$ and the $\mathrm{O}^{\beta 3}$ atom increased from 1.75 to $2.00 \AA$ (Figure 4). The associative or dissociative character of the transition state was estimated using Pauling's formula: $\mathrm{D}(n)=\mathrm{D}(1)-0.6 \log$ $n .^{53}$ Here, $\mathrm{D}(1)$ is $1.73 \AA$ for the $\mathrm{P}-\mathrm{O}$ bond and $\mathrm{D}(n)$ is the average of $r_{\mathrm{O}^{1}-\mathrm{P}^{\gamma}}$ and $r_{\mathrm{P}^{\gamma}}-\mathrm{O}^{\beta 3}$ at the transition state $(2.03 \AA)$. The fractional bond number $(n)$ is 0.32 , which gives a dissociative character of $68 \%$. Thus, the phosphoryl transfer in GALK occurs through a dissociative-dominated mechanism. The calculated activation barrier is $20.8 \mathrm{kcal} / \mathrm{mol}$, in accordance with a previous kinetics study $\left(k_{\text {cat }}=4.7 \pm 0.2 \mathrm{~s}^{-1}\right)$ that showed that the phosphorylation reaction catalyzed by human GALK occurs very readily. ${ }^{54}$

Arg228, Glu174, and Arg105 in human GALK were mutated in order to understand the effect of the mutations on the 


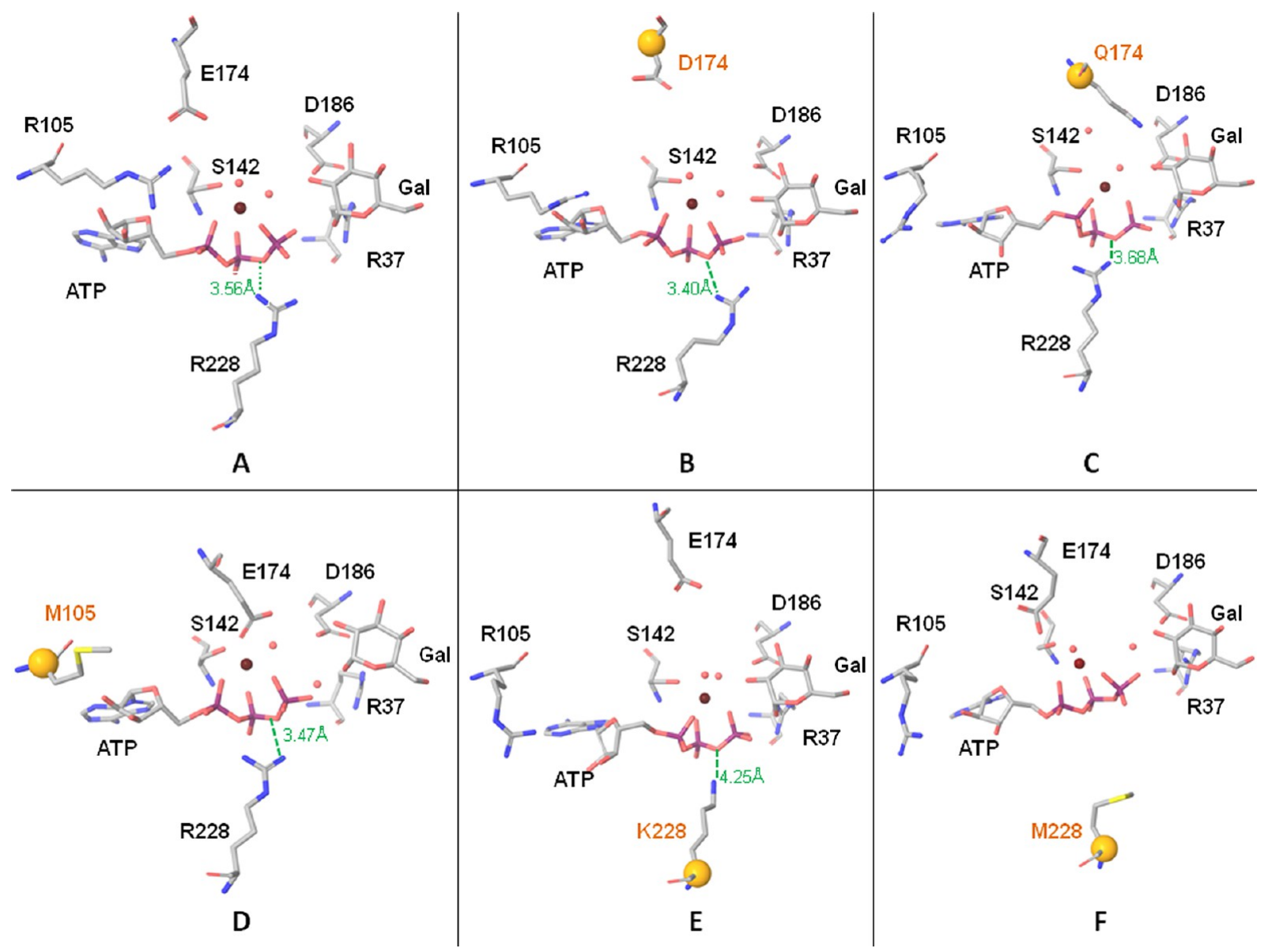

Figure 5. Mutated human GALK structures from MD simulations. The Mg ion is shown in maroon, and the oxygen atoms in the structural water molecules are shown by red balls. The $\mathrm{C} \alpha$ atoms of the mutated residues are shown in orange by CPK mode. (A) The wild-type human GALK, (B) E174D, (C) E174Q, (D) R105M, (E) R228K, and (F) R228M.

conformation of the active site. When Arg228 is mutated into neutral methionine, Arg105 failed to access the active site (Figure 5). One structural water molecule moved away, yielding an unstable pentacoordinated $\mathrm{Mg}^{2+}$ ion. Interestingly, when Arg228 was replaced by a conservative lysine, Arg105 remained far from Glu174. This suggests Arg228 helps to grasp Arg105 in the proximity of the active site in wild-type human GALK.

Little effect was observed for conservative replacement of Glu174 with an aspartate, although Arg105 is not as close to the catalytic center as is the wild-type GALK. Arg228 is positioned preferably toward the $\beta, \gamma$-bridging oxygen atom of ATP, and the hydrogen atom on the $\mathrm{Cl}$ hydroxyl group of galactose is well-positioned toward the oxygen atom of $\gamma$-phosphate. However, when Glu174 was replaced by a neutral glutamine, the octahedral coordination of the $\mathrm{Mg}^{2+}$ ion is distorted because of drifting of the $\mathrm{Mg}^{2+}$ ion and a catalytic water molecule.

Replacement of Arg105 by a neutral methionine caused drifting of all the ligands. Glu174 moved toward the reaction center such that it was eventually covalently bonded to the $\mathrm{Mg}^{2+}$ ion, replacing one catalytic water molecule in the wildtype GALK. Proximity of the negatively charged Glu174 makes the trigonal-bipyramidal transition state highly unstable. Thus, in addition to Arg228, it may be essential to have Arg105 as the second positively charged residue in the ATP binding site to further stabilize the charge in the unusual oxyanion hole of GALK.
Thus we propose it is important to have a positively charged arginine Arg228 around the $\beta, \gamma$-bridging oxygen atom of ATP to stabilize the coordination environment of the $\mathrm{Mg}^{2+}$ ion. It helps to bring a second positively charged residue (Arg105) to the proximity of ATP. Glu174 and Arg105 are also important in stabilizing the octahedral coordination, although they are not indispensable for retaining Arg228 around ATP.

Lys101 located on the P-loop in the active site of PMK was suggested to stabilize both the reactant and the transition state of the kinase. ${ }^{55}$ The residue is not conserved in GHMP kinases (Figure 2). However, a cationic residue located in the proximity of the $\beta, \gamma$-bridging oxygen is observed in many GHMP kinase structures, for example, Lys234 in human GALK2, ${ }^{25}$ Lys192 in P. furiosus GALK, ${ }^{5}$ Lys 266 in S. cerevisiae Gallp ${ }^{4}$, and Lys 258 in S. cerevisiae Gal3p. ${ }^{56}$ These lysine residues are all located at a loop adjacent to their respective P-loops (Figure 6 and Supporting Information, Figure S5). Comparison of the reactants and products of human GALK and GALK2 showed that the distal guanidinium nitrogen atom of Arg228 is $4.07 \AA$ from the $\beta, \gamma$-bridging oxygen in human GALK, whereas the $\varepsilon$ amino nitrogen atom of Lys 234 is closer to the $\beta, \gamma$-bridging oxygen in GALK2 (with the $r_{\mathrm{O}}{ }^{\beta 3}-\mathrm{N}^{\mathrm{K} 234}$ of $2.96 \AA$ ) and the $\gamma$ phosphate is better positioned for the nucleophilic attack by the sugar substrate GalNAc (with $r_{\mathrm{P}^{\gamma}-\mathrm{O}^{1}}$ of $3.10 \AA$ ) (Supporting Information, Figure S6). In the phosphorylation products of both kinases, the arginine or lysine further approaches the $\beta, \gamma$ bridging oxygen and the distances $r_{\mathrm{O}}{ }^{\beta 3}-\mathrm{N}^{\mathrm{K} 234}$ and $r_{\mathrm{O}}{ }^{\beta 3}-\mathrm{N}^{\mathrm{R} 228}$ 

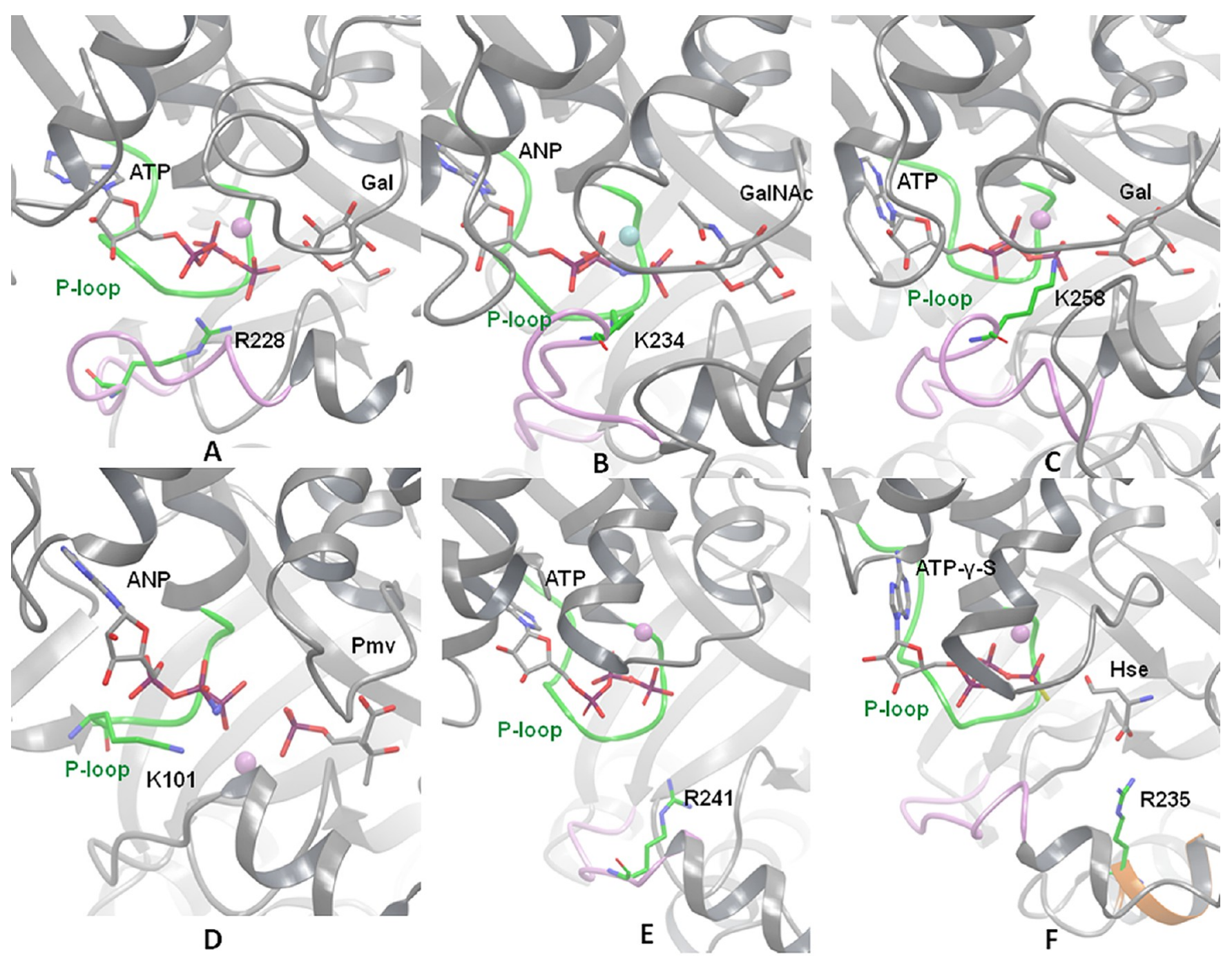

Figure 6. Location of the lysine or arginine residues near the P-loops of GHMP kinases. The figure was generated by superimposing the conserved motifs I and II of the GHMP kinases. P-loops are shown in green. The loop on which Arg228 is located in GALK is shown in plum, and helix Arg235 in HSK is shown in orange. (A) QM/MM-optimized reactant of human GALK, (B) reactant of human GALK2 (PDB code 2A2D), (C) gal3p (PDB code 3V2U), (D) Spn-PMV (PDB code 3GON), (E) rat MK (PDB code 1KVK), and (F) Mja-HSK (PDB code 1H74). The pose of Hse was modeled based on the structure of HSK bound with ANP (PDB code 1H72).

become similar to each other. Thus, Arg228 in human GALK may play a role similar to that of the lysine in other GALK and PMK kinases by stabilizing the negative charge developed on the $\beta, \gamma$-bridging oxygen atom during bond cleavage. It is worth noting that $\operatorname{Arg} 228$ is far from the $\beta, \gamma$-bridging oxygen $\left(r_{\mathrm{O}}{ }^{\beta 3}-\mathrm{N}^{\mathrm{R} 228}\right.$ is $\left.7.30 \AA\right)$ in the crystal structure of human GALK, which represents an inactive configuration. However, with time evolution, it gradually approaches the active site because of the flexibility of the loop on which it is located and therefore exerts its function in phosphorylation.

Arg241 in the mammalian MK is invariantly present in $\mathrm{MK}$ kinases and was proposed to stabilize the substrate by forming an ionic bond with the carboxylic group of mevalonate. ${ }^{20}$ Similar to Arg228 in GALK, Arg241 in the crystal structure of the mammalian $\mathrm{MK}$ is located on the surface loop adjacent to the P-loop (Figure 6), although it is also far from the $\beta, \gamma$ bridging oxygen $(7.77 \AA)$ (Supporting Information, Figure S7). ${ }^{20}$ Thus, we speculate the crystal structure of MK is also in its inactive configuration and the arginine in the vicinity of the P-loop may approach the triphosphate tail of ATP through substantial conformational change to stabilize the negative charge that develops at the $\beta, \gamma$-bridging oxygen of ATP during bond cleavage.

Arg234, an invariant arginine in HSK kinases, was found to be essential for the catalytic efficiency of Escherichia coli HSK by forming a strong salt bridge with the carboxylate of Hse. ${ }^{24}$ Surprisingly, the conserved Arg235 in Methanocaldococcus jannaschii HSK is located on a helix far from the ATP binding pocket (Figure 6). The absence of a cationic residue in the triphosphate binding pocket makes HSK distinct from other GHMP kinases. Arg235 may participate in stabilizing the $\beta, \gamma$ bridging oxygen of ATP facilitated by the surrounding water molecules. Further investigation is required to elucidate the reaction pathway in HSK and understand the difference in mechanism among GHMP kinases.

Recently, several small lead compounds were reported to selectively inhibit GALK with high potency. ${ }^{14}$ Among them, compound 24 forms H-bond interactions with Arg228, Glu174, and Arg105. Because Arg228 is not conserved among GHMP kinases, reagents which form interactions with Arg228, and 
therefore can interrupt its function in the phosphorylation, may be developed into potential selective inhibitors for GALK. On the other hand, substrate specificity of the kinase may be broadened by altering Arg228 as well as the loop where it is located in relation to the corresponding loops in other GHMP kinases.

\section{CONCLUSION}

The GHMP kinase superfamily plays a significant role in various biological pathways. Previously, there was no detailed mechanistic study at the atomic level for the GHMP kinase superfamily. Here, GALK involved in the first committed step in the Leloir pathway was studied in detail by combined molecular dynamics and hybrid QM/MM methods. We demonstrated that Glu174 captured Arg105 in the proximity of ATP via an H-bond network, thus restricting the movement of ATP in the large anion hole. Because of the loop flexibility, Arg228 approaches the ATP and stabilizes the negative charge developed at the $\beta, \gamma$-bridging oxygen atom of the ATP during bond cleavage. The optimized structure of the transition state and the reaction pathway obtained by $\mathrm{QM} / \mathrm{MM}$ study disclosed that the mechanism is direct phosphorylation, via a trigonalbipyramidal transition state.

\section{ASSOCIATED CONTENT}

\section{S Supporting Information}

The parameters for galactose, magnesium ion, and ATP; a movie of MD simulation; and the coordinates of the stationary points on the PES surface. This material is available free of charge via the Internet at http://pubs.acs.org.

\section{AUTHOR INFORMATION}

\section{Corresponding Author}

*School of Chemistry and Chemical Engineering, Queen's University Belfast, David Keir Building, Stranmillis Road, Belfast BT9 5AG, U.K. Tel: (44) 28-9097-4698. Fax: (44) 28-9097-6524. E-mail: m.huang@qub.ac.uk.

\section{Notes}

The authors declare no competing financial interest.

\section{ACKNOWLEDGMENTS}

The computing facility of Queen's University Belfast high performance computing centre is acknowledged. The authors gratefully appreciate helpful discussion with Prof. Adrian Mulholland from University of Bristol.

\section{ABBREVIATIONS}

$\mathrm{QM} / \mathrm{MM}$, quantum mechanics/molecular mechanics; GALK, galactokinase; HSK, homoserine kinase; MK, mevalonate kinase; PMK, phosphomevalonate kinase; GALK2, $\mathrm{N}$-acetylgalactosamine kinase; PoK, pantoate kinase; EGFR, epidermal growth factor receptor; $\mathrm{CDK}$, cyclin-dependent protein kinases; TS, transition state; MD, molecular dynamics; DFT, density functional theory; PES, potential energy surface; Hse, homoserine; RMSD, root-mean-square deviation

\section{REFERENCES}

(1) Bork, P., Sander, C., and Valencia, A. (1993) Convergent evolution of similar enzymatic function on different protein folds: The hexokinase, ribokinase, and galactokinase families of sugar kinases. Protein Sci. 2, 31-40.
(2) Holden, H. M., Thoden, J. B., Timson, D. J., and Reece, R. J. (2004) Galactokinase-structure, function and role in type II galactosemia. Cell. Mol. Life Sci. 61, 2471-2484.

(3) Thoden, J. B., Timson, D. J., Reece, R. J., and Holden, H. M. (2005) Molecular structure of human galactokinase: Implications for type II galactosemia. J. Biol. Chem. 280, 9662-9670.

(4) Thoden, J. B., Sellick, C. A., Timson, D. J., Reece, R. J., and Holden, H. M. (2005) Molecular structure of Saccharomyces cerevisiae Gallp, a bifunctional galactokinase and transcriptional inducer. J. Biol. Chem. 280, 36905-36911.

(5) Hartley, A., Glynn, S. E., Barynin, V., Baker, P. J., Sedelnikova, S. E., Verhees, C., de Geus, D., van der Oost, J., Timson, D. J., Reece, R. J., and Rice, D. W. (2004) Substrate specificity and mechanism from the structure of Pyrococcus furiosus galactokinase. J. Mol. Biol. 337, 387-398.

(6) Hoffmann, G., Gibson, K. M., Brandt, I. K., Bader, P. I., Wappner, R. S., and Sweetman, L. (1986) Mevalonic aciduria-an inborn error of cholesterol and nonsterol isoprene biosynthesis. N. Engl. J. Med. 314, $1610-1614$

(7) Houten, S. M., Kuis, W., Duran, M., Ade Koning, T. J., van Royen-Kerkhol, A., Romeijn, G., Frenkel, J., Dorland, L., Ade Barse, M. M. J., Huijbers, W. A. R., Rijkers, G. T., Waterham, H. R., Wanders, R. J. A., and Poll-The, B. T. (1999) Mutations in MVK, encoding mevalonate kinase, cause hyperimmunoglobulinemia $\mathrm{D}$ and periodic fever syndrome. Nat. Genet. 22, 175-177.

(8) Drenth, J. P., Cuisset, L., Grateau, G., Vasseur, C., van de VeldeVisser, S. D., de Jong, J. G., Beckmann, J. S., van der Meer, J. W., and Delpech, M. (1999) Mutations in the gene encoding mevalonate kinase cause hyper-IgD and periodic fever syndrome. International Hyper-IgD Study Group. Nat. Genet. 22, 178-181.

(9) Segal, S., and Berry, G. T. (1995) Disorders of galactose metabolism. In The Metabolic and Molecular Basis of Inherited Disease (Scriver, C. R., Beaudet, A. L., Sly, W. S., and Valle, D., Eds.) pp 9671000, McGraw-Hill, New York.

(10) Petry, K. G., and Reichardt, J. K. (1998) The fundamental importance of human galactose metabolism: Lessons from genetics and biochemistry. Trends Genet. 14, 98-102.

(11) Novelli, G., and Reichardt, J. K. (2000) Molecular basis of disorders of human galactose metabolism: Past, present, and future. Mol. Genet. Metab. 71, 62-65.

(12) Bosch, A. M., Bakker, H. D., van Gennip, A. H., van Kempen, J. V., Wanders, R. J., and Wijburg, F. A. (2002) Clinical features of galactokinase deficiency: A review of the literature. J. Inherited Metab. Dis. 25, 629-634.

(13) Wierenga, K. J., Lai, K., Buchwald, P., and Tang, M. (2008) High-Throughput Screening for Human Galactokinase Inhibitors. J. Biomol. Screening 13, 415-423.

(14) Tang, M., Wierenga, K., Elsas, L. J., and Lai, K. (2010) Molecular and biochemical characterization of human galactokinase and its small molecule inhibitors. Chem.-Biol. Interact. 188, 376-385.

(15) Odejinmi, S. I., Rascon, R. G., Tang, M., Vankayalapati, H., and Lai, K. (2011) Structure-Activity Analysis and Cell-Based Optimization of Human Galactokinase Inhibitors. ACS Med. Chem. Lett. 2, $667-672$.

(16) Tang, M., Odejinmi, S. I., Allette, Y. M., Vankayalapati, H., and Lai, K. (2011) Identification of Novel Small Molecule Inhibitors of 4diphosphocytidyl-2-C-methyl-d-erythritol (CDP-ME) kinase of Gramnegative bacteria. Bioorg. Med. Chem. 1, 5886-5695.

(17) Hoffmeister, D., Yangm, J., Liu, L., and Thorson, J. S. (2003) Creation of the first anomeric D/L-sugar kinase by means of directed evolution. Proc. Natl. Acad. Sci. U.S.A. 100, 13184-13189.

(18) Hoffmeister, D., and Thorson, J. S. (2004) Mechanistic implications of Escherichia coli galactokinase structure-based engineering. ChemBioChem 5, 989-992.

(19) Yang, J., Fu, X., Liao, J., Liu, L., and Thorson, J. S. (2005) Structure-based engineering of $E$. coli galactokinase as a first step toward in vivo glycorandomization. Chem. Biol. 12, 657-664.

(20) Fu, Z., Wang, M., Potter, D., Miziorko, H. M., and Kim, J. J. (2002) The structure of a binary complex between a mammalian 
mevalonate kinase and ATP: Insights into the reaction mechanism and human inherited disease. J. Biol. Chem. 277, 18134-18142.

(21) Potter, D., and Miziorko, H. M. (1997) Identification of catalytic residues in human mevalonate kinase. J. Biol. Chem. 272, 2544925454.

(22) Potter, D., Wojnar, J. M., Narasimhan, C., and Miziorko, H. M. (1997) Identification and functional characterization of an active-site lysine in mevalonate kinase. J. Biol. Chem. 272, 5741-5746.

(23) Megarity, C. F., Huang, M., Warnock, C., and Timson, D. J. (2011) The role of the active site residues in human galactokinase: Implications for the mechanisms of GHMP kinases. Bioorg. Chem. 39, 120-126.

(24) Krishna, S. S., Zhou, T., Daugherty, M., Osterman, A., and Zhang, H. (2001) Structural basis for the catalysis and substrate specificity of homoserine kinase. Biochemistry 40, 10810-10818.

(25) Thoden, J. B., and Holden, H. M. (2005) The Molecular Architecture of Human N-Acetylgalactosamine Kinase. J. Biol. Chem. 280, 32784-32791.

(26) (a) Timson, D. J., and Reece, R. J. (2002) Kinetic analysis of yeast galactokinase: Implications for transcriptional activation of the GAL genes. Biochimie 84, 265-272. (b) Timson, D. J., and Reece, R. J. (2003) Functional analysis of disease-causing mutations in human galactokinase. Eur. J. Biochem. 270, 1767-1774.

(27) Lefurgy, S. T., Rodriguez, S. B., Park, C. S., Cahill, S., Silverman, R. B., and Leyh, T. S. (2010) Probing ligand-binding pockets of the mevalonate pathway enzymes from Streptococcus pneumonia. J. Biol. Chem. 285, 20654-20663.

(28) Case, D. A., Darden, T. A., Cheatham, T. E., III, Simmerling, C. L., Wang, J., Duke, R. E., Luo, R., Crowley, M., Walker, R. C., Zhang, W., Merz, K. M., Wang, B., Hayik, S., Roitberg, A., Seabra, G., Kolossvary, I., Wong, K. F., Paesani, F., Vanicek, J., Wu, X., Brozell, S. R., Steinbrecher, T., Gohlke, H., Yang, L., Tan, C., Mongan, J., Hornak, V., Cui, G., Mathews, D. H., Seetin, M. G., Sagui, C., Babin, V., and Kollman, P. A. (2008) AMBER 10, University of California, San Francisco.

(29) Wang, J., Wolf, R. M., Caldwell, J. W., Kollman, P. A., and Case, D. A. (2004) Development and testing of a general Amber force field. J. Comput. Chem. 25, 1157-1174.

(30) Frisch, M. J., Trucks, G. W., Schlegel, H. B., Scuseria, G. E., Robb, M. A., Cheeseman, J. R., Scalmani, G., Barone, V., Mennucci, B., Petersson, G. A., Nakatsuji, H., Caricato, M., Li, X., Hratchian, H. P., Izmaylov, A. F., Bloino, J., Zheng, G., Sonnenberg, J. L., Hada, M., Ehara, M., Toyota, K., Fukuda, R., Hasegawa, J., Ishida, M., Nakajima, T., Honda, Y., Kitao, O., Nakai, H., Vreven, T., Montgomery, J. A., Jr., Peralta, J. E., Ogliaro, F., Bearpark, M., Heyd, J. J., Brothers, E., Kudin, K. N., Staroverov, V. N., Kobayashi, R., Normand, J., Raghavachari, K., Rendell, A., Burant, J. C., Iyengar, S. S., Tomasi, J., Cossi, M., Rega, N., Millam, J. M., Klene, M., Knox, J. E., Cross, J. B., Bakken, V., Adamo, C., Jaramillo, J., Gomperts, R., Stratmann, R. E., Yazyev, O., Austin, A. J., Cammi, R., Pomelli, C., Ochterski, J. W., Martin, R. L., Morokuma, K., Zakrzewski, V. G., Voth, G. A., Salvador, P., Dannenberg, J. J., Dapprich, S., Daniels, A. D., Farkas, Ö., Foresman, J. B., Ortiz, J. V., Cioslowski, J., and Fox, D. J. (2009) Gaussian 09, revision A.1, Gaussian, Inc., Wallingford, CT.

(31) Weiner, P. K., and Kollman, P. A. (1981) AMBER: Assisted model building with energy refinement. A general program for modeling molecules and their interactions. J. Comput. Chem. 2, 287303.

(32) Pastor, R. W., Brooks, B. R, and Szabo, A. (1988) An analysis of the accuracy of Langevin and molecular dynamics algorithms. Mol. Phys. 65, 1409-1419.

(33) Darden, T., York, D., and Pedersen, L. (1993) Particle mesh Ewald: An $\mathrm{N}-\log (\mathrm{N})$ method for Ewald sums in large systems. J. Chem. Phys. 98, 10089-10092.

(34) Ryckaert, J. P., Ciccotti, G., and Berendsen, H. J. C. (1977) Numerical integration of the cartesian equations of motion of a system with constraints: Molecular dynamics of $n$-alkanes. J. Comput. Phys. 23, $327-341$.
(35) Vreven, T., Byun, K. S., Komromi, I., Dapprich, S., Montgomery, J. A., Morokuma, K., and Frisch, M. J. (2006) Combining Quantum Mechanics Methods with Molecular Mechanics Methods in ONIOM. J. Chem. Theory Comput. 2, 815-826.

(36) Svensson, M., Humbel, S., Froese, R. D. J., Matsubara, T. Sieber, S., and Morokuma, K. (1996) ONIOM: A Multilayered Integrated $\mathrm{MO}+\mathrm{MM}$ Method for Geometry Optimizations and Single Point Energy Predictions. A Test for Diels-Alder Reactions and $\mathrm{Pt}\left(\mathrm{P}(t-\mathrm{Bu})_{3}\right)_{2}+\mathrm{H}_{2}$ Oxidative Addition. J. Phys. Chem. 100, 1935719363.

(37) Grimme, S. (2006) Semiempirical GGA-type density functional constructed with a long-range dispersion correction. J. Comput. Chem. 27, 1787-1799.

(38) Tao, P., and Schlegel, H. B. (2010) A toolkit to assist ONIOM calculations. J. Comput. Chem. 31, 2363-2369.

(39) Zhou, J., Tao, P., Fisher, J. F., Shi, Q., Mobashery, S., and Schlegel, H. B. (2009) Matrix Metalloproteinase 2 (MMP2) Inhibition: DFT and QM/MM Studies of the DeprotonationInitialized Ring-Opening Reaction of the Sulfoxide Analogue of SB3CT. Biochemistry 48, 9839-9847.

(40) Li, H., Robertson, A. D., and Jensen, J. H. (2005) Very Fast Empirical Prediction and Rationalization of Protein $\mathrm{p} K_{\mathrm{a}}$ Values. Proteins 61, 704-721.

(41) Bas, D. C., Rogers, D. M., and Jensen, J. H. (2008) Very fast prediction and rationalization of $\mathrm{p} K_{\mathrm{a}}$ values for protein-ligand complexes. Proteins 73, 765-783.

(42) Lonsdale, R., Harvey, J. N., and Mulholland, A. J. (2012) A practical guide to modelling enzyme-catalysed reactions. Chem. Soc. Rev. 41, 3025-3038.

(43) Walker, J. E., Saraste, M., Runswick, M. J., and Gay, N. J. (1983) Distantly related sequences in the $\alpha$ - and $\beta$-subunits of ATP synthase, myosin, kinases and other ATP-requiring enzymes and a common nucleotide binding fold. EMBO J. 1, 945-951.

(44) Hanson, P. I., and Whiteheart, S. W. (2005) AAA+ proteins: Have engine, will work. Nat. Rev. Mol. Cell Biol. 6, 519-529.

(45) Pilloff, D., Dabovic, K., Romanowski, M. J., Bonanno, J. B., Doherty, M., Burley, S. K., and Leyh, T. S. (2003) The kinetic mechanism of phosphomevalonate kinase. J. Biol. Chem. 278, 45104515.

(46) Zhou, T., Daugherty, M., Grishin, N. V., Osterman, A. L., and Zhang, H. (2000) Structure and Mechanism of Homoserine Kinase: Prototype for the GHMP Kinase Superfamily. Structure (Oxford, U.K.) 8, 1247-1257.

(47) Yang, D., Shipman, L. W., Roessner, C. A., Scott, A. I., and Sacchettini, J. C. (2002) Structure of the Methanococcus jannaschii Mevalonate Kinase, a Member of the GHMP Kinase Superfamily. J. Biol. Chem. 277, 9462-9467.

(48) Shi, T., Lu, Y., Liu, X., Chen, Y., Jiang, H., and Zhang, J. (2011) Mechanism for the Autophosphorylation of CheA Histidine Kinase: QM/MM Calculations. J. Phys. Chem. B 115, 11895-11901.

(49) Shi, F., Telesco, S. E., Liu, Y., Radhakrishnan, R., and Lemmona, M. A. (2010) ErbB3/HER3 intracellular domain is competent to bind ATP and catalyze autophosphorylation. Proc. Natl. Acad. Sci. U.S.A. 107, 7692-7697.

(50) Smith, G. K., Ke, Z., Guo, H., and Hengge, A. C. (2011) Insights into the phosphoryl transfer mechanism of cyclin-dependent protein kinases from ab initio QM/MM free-energy studies. J. Phys. Chem. B $115,13713-13722$

(51) Tomita, H., Yokooji, Y., Ishibashi, T., Imanaka, T., and Atomi, H. (2012) Biochemical characterization of pantoate kinase, a novel enzyme necessary for coenzyme A biosynthesis in the Archaea. $J$. Bacteriol. 194, 5434-5443.

(52) van der Kamp, M. W., and Mulholland, A. J. (2013) Combined Quantum Mechanics/Molecular Mechanics (QM/MM) Methods in Computational Enzymology. Biochemistry 52, 2708-2728.

(53) Mildvan, A. S. (1997) Mechanisms of Signaling and Related Enzymes. Proteins 29, 401-416.

(54) Kristiansson, H., and Timson, D. J. (2011) Increased Promiscuity of Human Galactokinase Following Alteration of a Single 
Amino Acid Residue Distant from the Active Site. ChemBioChem 12, 2081-2087.

(55) Andreassi, J. L., Vetting, M. W., Bilder, P. W., Roderick, S. L., and Leyh, T. S. (2009) Structure of the Ternary Complex of Phosphomevalonate Kinase: The Enzyme and Its Family. Biochemistry 48, 6461-6468.

(56) Lavy, T., Kumar, P. R., He, H., and Joshua-Tor, L. (2012) The Gal3p transducer of the GAL regulon interacts with the Gal80p repressor in its ligand-induced closed conformation. Genes Dev. 26, 294-303. 